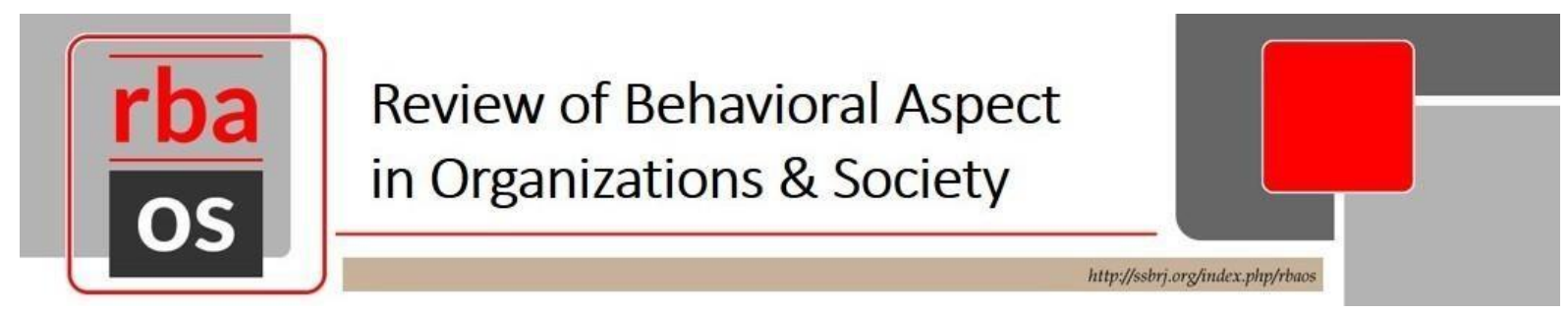

\title{
THE CONUNDRUM OF INTERNET OF THINGS ADOPTION IN HIGHER EDUCATIONAL INSTITUTIONS
}

\author{
Amy Yeo Chu May, TAR UC, Malaysia \\ Tan Gim Guan, Roche Pharmaceutical, Malaysia \\ Professor Steve Carter, Heriot-Watt University, United Kingdom
}

\begin{abstract}
This study aims to extend the evaluation and understanding of an individuals' adoption intention towards the Internet of Things (IoT) in a higher educational context and also to assess the relationship between Perceived Benefits, Digital Culture and Mindset, Technological Motivator, Technological Inhibitor and Attitude and how these factors relate to the adoption of Internet of Things (IoT) behavior. The research employed a quantitative and cross-sectional approach. A sample of 202 respondents from a Malaysian educational institution was collected through a self-designed questionnaire based on a snowball sampling technique. The data collected were analyzed using SmartPLS. The results indicate that attitude, technological motivator and digital mindset have a significant effect on the IoT adoption intention. Of these, attitude has the greatest influence with regard to the decision to adopt any IoT products or services. Digital mindset was a salient factor that explained user's adoption intention behaviour on IoT technologies. Perceived benefits, however, showed insignificant direct effect whereas the technological inhibitor perspective affects the IoT adoption intention through attitude factor. The research provides further evidence that attitude and digital mindset built up within the individual are crucial elements to be considered in justifying the adoption behavior of IoT. The research findings show how the adoption of IoT could help academic staff and students leverage technologies' benefits to improve work and academic performance. It also highlights the importance of trust and builds the required attitude to support the technology to industry players. This study did not account for motivators such as incentives or influence from authority figures (leaders, top management, government and policy maker) as well as environmental conditions, namely the readiness of the infrastructure and the commonality of the usage in the social group.

Keywords: Internet of Things, digital mindset, trust, attitude, adoption behaviour
\end{abstract}




\section{Introduction}

The Internet of Things (IoT), the connection of devices to the internet, is in the process of transforming many areas of our daily lives. Intelligent interactivity between human and things, to exchange information and knowledge, is part of the rapid development and adoption of the Internet of Things (IoT) in various industries (e.g. Financial Services, Insurance, Entertainment, Social Media and Telecommunication, Retail, Healthcare, Manufacturing) and education is one of the 'industries' which is on the impact list (Aldowah et al. 2017). With the arrival of Web 2.0 in the early 2000s, the web has evolved to become more than a giant shopping mall and online encyclopedia (Schmidt and Rosenberg 2014). People can do all sorts of things online via smart connected devices. In a similar vein, Mahbub (2020) found that billions of people from around the world are connected to each other and share data online.

According to Vaidya, Ambad, and Bhosle (2018), Industrial 4.0 is empowering transformation for enterprises, consumers and governments alike. Emerging tools and technologies like machine learning, artificial intelligent, big data analytics, the Internet of Things (IoT) are enabling huge gains in efficiency and more control in the home, workplace and schools. The Internet of Things (IoT) has been developed at a very fast pace over the last 5 years and has deeply rooted itself in various industries including higher education. For instance, e-learning (or remote virtual learning) has become common practice in the Western education system, the rise of mobile technology and the common application of IoT allows schools to improve the efficiency of teaching, promote easy and fast access to information and many other uses like student application systems.

As such, technology and educational organisation, influence each other more and more and analytical efforts to treat these as distinct conceptual units are constantly being called into question (Boos et al. 2012). By implementing the Internet of Things (IoT) technologies in education, a better connection and collaboration among students may be achieved, particularly students with lecturers, or lecturers with lecturers via connected devices and facilities. In fact, some of the actual applications of IoT in educational institutions are already in place as part of the environment. Through IoT, students are offered better access to everything from learning materials, teaching facilities, study performance results to communication channels. For faculty staff, it also provides a new way of interacting with students and improves the ability to measure student learning progress in real-time, a phenomenon known as part of the 'personalization of the education experience'.

With the arrival of the digital age in the last decades, technology advancement, especially in digital related areas have introduced new practices, opportunities, and ways of thinking. This helps the inculcation and evolution of the culture and mindset of people to a more 'digital' model hence the need to find appropriate ways to respond to this new reality (Uzelac 2010). Therefore, it is essential to understand how IoT adoption in Higher Educational Institutions could affect teaching and the learning experience and improve decision-making in management's strategic planning processes in order to be able to achieve expected benefits. Hence, it is essential to explore some plausible antecedents that might or might not influence the adoption of the Internet of Things (IoT).

Several studies have examined the impact of Industry 4.0, Cloud technology, Internet of Things (IoT) in various industries, mainly in the technology advanced countries like United States, Germany and China etc. These studies tend to portray the importance of the IoT from the 
technical architecture, design and implementation standpoints (Khan et al. 2012; Gubbi et al. 2013; Sundmaeker et al. 2010; Uckelmann et al. 2011). Many studies also have focused on the antecedents of Internet of Things usage (Alsaadi 2015; Timon et al. 2018; Tianbo, 2012). However, developing countries like Malaysia have received relatively little attention on the topic. Furthermore, not many have focused on the motivators and barriers that promote or prevent the adoption of IoT as well as the digital and innovation mindset and culture readiness context. Recent research by Newman (2019) suggested that digital transformation is a mindset and culture evolution, it has to begin with the culture change and the readiness to accept and practice the change. It is the key to decide the success or failure of the transformation. Consequently, the urge to understand more on IoT adoption and its impacting factors is increasingly becoming more crucial. As such, this research has been carried out to fill that theoretical fissure by investigating the various interrelated factors that influence the IoT adoption in the context of higher education. The study therefore aims to assess the relationship between the perceived antecedents (Perceived Benefits, Digital Culture and Mindset, Technological Motivator, Technological Inhibitor, Attitude) and how these factors could possibly influence the adoption of IoT. In addition, we put forward the following research questions:

RQ1. What are the benefits that encourages student to accept and adopt IoT applications?

RQ2. Do students in higher educational institutions have the strong digital mindset and interest in the IoT applications?

RQ3. What are the technological drivers and barriers that promote and hinder the adoption of IoT applications?

\section{Literature Review}

Perceived benefits and adoption of the Internet of Things

According to research conducted by Alhogail (2018), perceived benefits are a major element of behavioral intention to the adoption of new technology, including the Internet of Things. Perceived benefits are interpreted as the degree to which an individual believes that using the Internet of Things technology would enhance their study/work/life performance (Hsu and Lin 2016). The perceived benefits of IoT services advocates that individuals will feel that such services will enable them to enhance their overall performance in daily tasks either professionally or personally related. As a result, it improves the quality of life, enables more leisure time or time spare with loved one and so, overall, a better work (or, study) life balance.

In many success stories in various industries, innovative new products and services must convince the user that technology will deliver benefits and can be used by people who can enjoy the advantages (Trott 2017). In a literature study conducted by Lee et al. (2011), they found that relative advantage acts significantly and positively in adoption of technology. Apart from the benefits that it brings to the individual, with the innovation and digital mindset in place, IoT technology can be applied to the building and designing of a smart educational campus. For example, one can imagine a green building with intelligent energy management, interacting with smart appliances to facilitate meeting rooms, lecture hall reservations, automatically detecting emergencies based on data collected via electronic sensors to enforce environmental safety. The perceived benefit of the IoT technology must be advocated to achieve successful adoption of the IoT. Therefore, we formulate the following hypothesis:

Hypothesis 1: Perceived Benefits relates positively to the adoption of Internet of Things 


\section{Linking digital mindset to the adoption of the Internet of Things}

In today's increasingly connected world, digital life is inextricably associated with a person's physical life. Having a presence in the digital world has evolved rapidly in the past two decades so a digital way of thinking has become a necessity. Through various digital presences such as Facebook, Twitter, LinkedIn, Instagram profile, people are able to consume and share information, express ideas, develop virtual relationships with anyone, anywhere in the world (Ridley 2015). All these are interrelated to the Internet of Things and the digital mindset is the catalyst behind the scenes that empowers the adoption of a digital living style. A user (can be leadership group, academic lecturer, administration staff, student) with a digital mindset is curious about digital technology and is always up-to date with the latest innovations. As there has been very little research undertaken into the effect of the digital mindset in the context of adoption behavior, this research study also relies to a certain extent on innovation readiness and culture described in the Technological Acceptance Model (TAM) and Innovation Diffusion Model (IDM).

Internet of Things (IoT) products and services involve consumption pattern changes for the user, which means it requires users to alter their previous or existing thinking and habits and this can affect their willingness to embrace the new technology trend (Schwab 2016). A way to get familiar with new product or service is via constant user interaction. The nature of change involved in the user mindset to get familiar with a new product or service can play a significant role in the adoption level (Veryzer et al. 2003). A person with a digitally predisposed mindset would always intend to use digital technology for educational, professional and personal leisure or learning purposes. A leader or manager with a digital mindset is curious about digital technology and is always up-to date with the latest innovations. Those who possess the digital mindset are more flexible and open-minded to new ideas and innovative technologies including the Internet of Things and always welcome change (Goethals et al. 2004). Compared to those who do not, he or she is more willing and keen to apply digital technology in their daily practice for professional or personal leisure purposes. As such, it can be concluded that an individual with a digital mindset is the one with the curiosity to learn and acquire knowledge about digital technology and he or she is predisposed to leverage the convenience of technology. So, the desire to use new technologies might be highly influenced by the digital mindset. In the commercial environment, a leader who possesses the digital mindset might be more inclined to integrate new technologies into the company than someone who does not have the mindset. It can be the same in the educational environment where a visionary leader who can foresee future trends is likely to more willing to invest time, resources and effort to ensure that the organization does not fall behind the latest technology trend from hardware facility to soft skill development. The absence of digital thinking and inadequate training as the barriers to innovation has been the subject of multiple studies (Geissbauer et al. 2016).

Based on Benke (2013)'s finding, the digital mindset is very different from the conventional transactional thinking. It includes digital technology and its impact on society and individual behavior. It can influence user behavior in recognizing and adopting digital technology including, but not limited to, the Internet of Things (IoT) initiatives. So the digital mindset and culture could effect hugely how individuals make their choice in selecting the usage of IoT products and services.

Thus, it is expected that the Digital Culture and Mindset has a significant effect toward IoT adoption. This leads us to the second hypothesis: 
Hypothesis 2: Digital Mindset relates positively to the adoption of Internet of Things

\section{The link between technological motivator and adoption of Internet of Things}

Thanks to the advancement in various disruptive technology, smart devices today, by default, come with high capability in processing power and storage while their reduced size facilitate ease of use. These smart devices are usually equipped with different type of sensors and actuators which allow them to link and communicate with the other devices which are connecting to the Internet seamlessly (Khan et al. 2012). By utilizing the convenience of IoT, the lecturer now has the ability to increase the learning experience by providing real-time and actionable insights into student performance. Advanced e-learning applications (e.g. Google Classroom, Google Drive on Cloud, Google Online Survey Form, Interactive Video etc) allow students to learn at their own pace and have an identical learning experience in classrooms and homes. Video management and content sharing tools, for example, Kaltura, allow students and teachers to create and share high quality learning video material with the aim to increase interaction and innovation to enrich overall learning experiences in school. Another good example is facial recognition through IoT technologies; iPads, Xboxes and video systems can use face recognition. Universities are gradually moving away from textbooks to new technologies to gain access to certain teaching materials or courses. Moreover, through IoT technologies, lecturers can collect data about students' learning progress (assignment submission, Q\&A, Virtual group chat discussion) and customize the teaching pace, or pay more attention to those who need more guidance (Aldowah et al. 2017).

With good knowledge and understanding of how technology works, people are more motivated to accept the Internet of Things's (IoT) products and services. Developing skills and stretching creative competences at the individual level is important in IoT adoption. With proper skills and knowledge, people can view the adoption from a positive angle i.e. that it comes with various advantages such as increased and faster interconnection between individuals remotely and virtually, faster information dissemination and exchange to ease study and work life, so more efficient use of time and resources (Schwab 2016).

With this finding, the third hypothesis is proposed:

Hypothesis 3: Technological Motivator has a positive effect on the adoption of Internet of Things

\section{Technological inhibitor and adoption of Internet of Things}

The difficulty of use plays a significant barrier role in the adoption rate and can impose an unbelievably negative impact to usage measures (Fusilier and Durlabhji 2005). In many situations, the complexity and availability of infrastructure technologies in the education institute are the main reasons for the reluctance to apply IoT due to the various challenges faced (ease of use, functionality compatibility, access control, data security and privacy governance etc). Essential connectivity requirements include internet scalability, high performance network and high capacity bandwidth and the need for standardisation to connect and integrate technologies (Atzori et al. 2010, Porter and Heppelmann 2015). Additional technological inhibitors are the implementation of hardware or software measures to prevent any unauthorized data access. The lack of relevant technology knowledge and skills also can result in a roadblock to the adoption of new technologies such as worries about privacy and potential surveillance, concern overidentity theft, and a feeling of a lack of transparency where individuals are not privy to information algorithms (Schwab 2016). Privacy is one of the top topics in the list in discussing the application of Internet of Things (IoT) because of the massive 
volume and granularity of personal data collected and shared through smart devices and sensors (Howard 2015). Besides, some studies have suggested that the unattractive appearance and limited functionality of current IoT devices such as wearable have prevented the user from adopting the IoT device. In other words, user friendliness and the design of the application have significant impact on the user experience whether the interaction is a pleasurable or unpleasurable one, hence can influence the adoption behavior (Stamm 2008). Based on the findings, we assume the 4th hypothesis:

Hypothesis 4. Technological Inhibitor is negatively related to the adoption of the Internet of Things

\section{The relationship between attitude and adoption of the Internet of Things}

As users have experienced and enjoyed the value of personalised services, they have relaxed their grip on accessing personalised data e.g. age, job profession, area of interest, subject of study, specialty etc., and are open to engage themselves with the IoT related products and services. Users who assign higher importance to digitalized products are more likely to engage in the development and dealing with IoT applications. The structural results indicate that users' attitude toward IoT technologies is a crucial predictor of their intention to use and adopt IoT (Park et al. 2017). Karahoca, Karahoca and Aksöz (2018) too found that attitude is an important determinant that indicates the level of an individual's favorable or unfavorable disposition towards a certain behaviour. As per the findings of Carter and Yeo (2016), students in a higher educational organisation tend to act more positively than negatively when dealing with technology and complex mobile and social media applications. Students treat it as a way to connect with family and friends hence the attitude to engage in the Internet of Things (IoT) and the connected devices to the internet is rather positive in student circles. Moreover, younger generations who are used to interacting with various electronic gadgets and smart devices e.g. laptops, mobile phones and iPads, are naturally more willing to accept and engage with mobile applications, which they found useful and help them to engage with others in the community. Jahanmir and Cavadas (2018) suggested that increasing the positive attitude of consumers toward a technology is a very powerful and effective approach in accelerating the adoption rate of new technology. There are numerous studies which revealed that there is a positive relationship between attitude and behavioral intention to adopt. Therefore, a positive attitude must be advocated to achieve a successful IoT adoption. With this, it led to the proposal of the $5^{\text {th }}$ hypothesis:

Hypothesis 5 (a): Attitude relates positively to the adoption of Internet of Things

\section{Intertwining between attitude, technological inhibitor and adoption of Internet of Things}

The Technological inhibitor plays an important role in relation to attitude, which can influence the adoption of the Internet of Things. In fact, the technological inhibitor, like premature infrastructure facilities, difficulties of using smart devices, and concerns over risks to information security, can be strong obstacles to attempts to gain positive interest and engagement behavior from IoT users. Without strong support from the users, applications of IoT technology will be primitive and fairly limited (Atzori et al. 2010). According to Peppet (2014), data security and privacy are huge concerns in using the Internet of Things (IoT) products and services. This can inhibit IoT adoption as people are uncertain if the data collected through smart sensors is well protected from unauthorized access and not intercepted by any unknown third party. The degree of security and privacy control offered by the product that 
provides connectivity to IoT create either a positive or negative user attitude, which can eventually affect the adoption to the IoT.

Based on research conducted by O'Brien and Toms (2008), it is important to understand how to design systems that make life easier and get things done faster, which can encourage user engagement via the use of technology. For example, in the education industry, educators should explore ways to critically engage students with the assistance of technology in the classroom (Salvo 2002) and in achieving a depth of engagement (Makkonen 1997) with computer applications. Technology knowledge and skill are essential attributes of engagement. Lacking this competency, can create challenges to an individual's engagement level (Skelly, Fries, Linnett, Nass and Reeves 1994). Therefore, it is clear that without that relevant technology skill set, it can hinder user engagement. This translates into the fact that technology challenge and inhibitor can be the "disengagement attributes" that affect the interest and engagement level of the users to the IoT application. Therefore, the technology knowledge (T-knowledge), defined as the capability and competency to operate with the technologies, is another key factor that can influence user engagement level, for instance, to help the user to be able to make prompt decisions in various domains by leveraging the internet to acquire supporting data and information (Cegarra et al. 2014). From research done by Wang et al. (2018), for the experienced internet users, perceived benefits have less impact on the adoption behavior. Their attitudes and intention to use are highly associated to their technological skills and habits.

According to Yi et al. (2006), user acceptance toward a technology is the major determinant of actual usage behaviour. In this case, the technological inhibitor can cause less user interest and engagement and thus negatively affect the adoption of the Internet of Things. Likewise, convenience of usage and a highly compatible interface with common smart devices in the market, help build a positive attitude toward IoT technologies. According to Chen et al. (2002), perceived ease of use is one of the prominent factors to explain the user's attitude. As a result, interest and the user's engagement attitude toward IoT technologies used in a smart environment (be it in the workplace, school or home) is believed to be closely determined by the perceived ease of use, hence associated with the technological motivator and inhibitor. In the past, many researchers have confirmed the impact of the technological barrier on both attitude and behavioral intention to adopt (Miltgen et al. 2013; Kim 2012; Wu and Wang 2005; Chen et al. 2002).

Given the estimated huge impact of IoT on industries in the next five years and the massive investment by the Government (InvestKL 2019) to ensure development to progress in this area, it is imperative to understand the user's level of interest and willingness to engage in this new technology. It is also equally important to identify the technological barrier affecting IoT user adoption among users in Malaysia. In order to do this, it is imperative to identify the factors that potentially stop the existing or new IoT users from accepting the technology.

Therefore, the 5(b) and 5(c) hypothesis are proposed here:

Hypothesis 5 (b): Technological Inhibitor is negatively related to the attitude.

Hypothesis 5(c): Attitude mediates the relationship between Technological Inhibitor and adoption of Internet of Things.

\section{Proposed conceptual framework}

The Technology Acceptance Model (Davis 1989) and Innovation Diffusion Theory (Rogers 2003) have been frequently applied by researchers to examine user behavior on acceptance and 
adoption of new technology. The Technology acceptance model (TAM) covers Perceived Usefulness (PU), Perceived Ease Of Use (PEU), Attitudes (AT) and Behavioral Intention (BI) factors and how these factors influences each other (Choi and Kim 2016; Davis 1989; Miltgen et al. 2013; Kim 2012; Wu and Wang 2005; Chen et al. 2002). The Innovation Diffusion Theory suggested that the rate of adoption of innovations is impacted by relative advantage (Rogers 1995). However, solely relying on TAM or IDT alone is inadequate to explain a potential adoption behavioral intention. Therefore, this research study proposed an integrated research model encompassing the technology acceptance, innovation diffusion, digital mindset and technological inhibitor context to form a more holistic view of factors affecting individuals' adoption to the Internet of Things (IoT) products and services in a Higher Education Institute. This research model covers two technological factors from technology acceptance model (TAM) and one factor from innovation diffusion theory (IDT) such as perceived benefits, attitude, technological motivator; one factor related to technological inhibitor and one new factor related to individual digital mindset.

Figure 1 shows the conceptual research model used in this study. The diagram provides a visualisation of the theoretical model that guided data collection and analysis for the study. The model shows that the technological inhibitor is the factor that affects user's attitude; it also elaborates how these factors influence the IoT adoption.

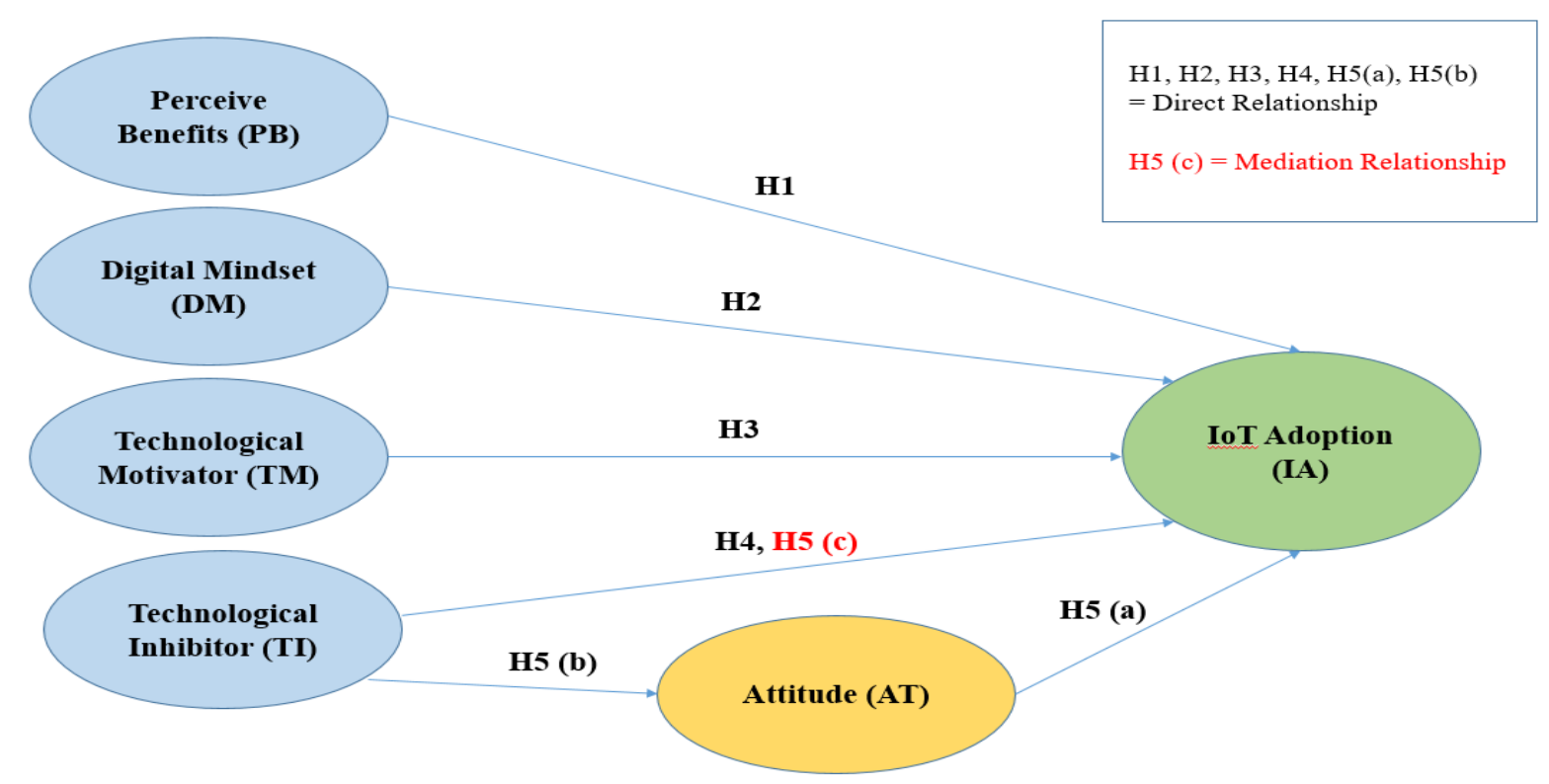

Figure 1: Conceptual Research Model

\section{Research Methodology}

Research design

This research was conducted by applying the quantitative study method. According to Creswell (2003), quantitative research involves collecting data from a large number of survey candidates within the specific, narrow, measurable constructs. According to Hoy and Curt (2016), 
construct refer to a term that has been given an abstract, generalized meaning. It helps the researcher to analyse trends, compare groups, or relating variables using a statistical approach and eventually interpreting results by comparing them with research conducted in the past (Creswell 2014). Quantitative research is the scientific investigation that includes both experiments and other systematic methods that emphasize control and quantified measures of performance (Proctor and Capaldi 2008). It is concerned with the development and testing of hypotheses and the generation of models and theories that elaborate behavior (Hoy and Curt 2016).

As part of the data gathering process of the research, a survey was conducted to validate the model by establishing the consensus of attitudes from a wide range of participants who have previously used the Internet of Things (IoT) products and services either directly or indirectly. The survey data was collected from the students in a Higher Education Institution in Malaysia through a self-administered questionnaire. The population for this survey consisted of students who were existing user of Internet of Things (IoT) products and services with different lengths of user experience, from several months to years and different levels of engagement in the IoT technologies. Prior to data collection, a briefing was delivered to the respondents to walk through the survey process and to ensure the questionnaire and their right as respondents were fully understood and acknowledged. Individuals participating in the study were assured of the confidentiality of their individual responses.

A cross-sectional study was used to examine existing attitudes, beliefs, opinions, or practices of the participants. Attitudes, beliefs, and opinions are ways in which individuals think about issues, whereas practice reflects the actual behaviours of the participants (Creswell 2014). The 6 page survey questionnaire consisted of 45 questions and 5 of them asked for demographic information such as gender, age, education qualification, and years of experience in using IoT products and services and frequency of use.

\section{Sampling design}

The survey data was collected from the target sample size of 250 undergraduate and postgraduate students of a Higher Educational Institution in Malaysia. The target population was mainly Generation Z (also known as "Post-Millennials") i.e. youngsters potentially who had used different types of IoT products and to a certain extent, used them in their daily lives. According to Ozkan and Solmaz (2015), Generation Z refers to those who were born after 2000. Their character and mindsets are different according to previous generations $\mathrm{X}$ and $\mathrm{Y}$. We delivered to each individual participant a paper survey form or online Google survey form and provided them clear instructions on how to answer the questions. For the paper survey form, the questions were presented in written format and respondents wrote their answers on the paper, whereas the online survey form was designed using Google forms as part of the G-Suite offering and respondents could answer the questionnaire online by accessing the URL provided. The online survey technique is gaining more popularity in academic research (Buchanan and Hvizdak 2009) with the convenience that responses are immediately available for analysis after the questionnaire is completed and submitted online. On many occasions, researchers may want to compare the result over time (Cozby and Bates 2012).

The questionnaire consisted of two parts. The first part contained the five questions to identify the demographic profiles of the participants. The second part of the questionnaire elaborated on the dependent variable and the independent variables, which were to be assessed in the survey. It contained sets of questions, which represented the three main dimensions of factors and were related to six factors of the trust model. The constructs consisted of dependent 
variables (Internet of Things Adoption Intention), independent variables (Perceived Benefits, Digital Mindset and Technology Motivator, Technology Inhibitor) and mediator variables (Attitude). To measure the importance of the items we used a Likert Scale (Likert, 1932). The Likert Scale is a psychometric scale that is commonly used in survey research (Diekmann 2007). We used a seven point Likert Scale ranging from "Strongly Disagree" via a "Neutral" statement to "Strongly Agree". The raw data collected were analysed using Partial least squares (PLS) path modeling. The advantages of PLS path modeling have been applied in many fields of research, from behavioral sciences studies (Bass et al. 2003) to business research, such as Marketing (Hair et al. 2014; Henseler et al. 2009), strategy (Hulland 1999), organisation (Sosik et al. 2009), and Management Information Systems (Ringle et al. 2012; Chin et al. 2003).

\section{Preliminary data analysis}

Common reasons of nonresponse can be categorized into several groups such as Not-at-home, Refusals, Unable to respond, and Un-located. According to research conducted by Atif, Richards, Bilgin (2015), in the situation where the survey ends up with a low response rate, there are possibilities that the data collected may not be conclusive enough and bias may exist due to non-response. As a result, the validity of the survey instrument may be questionable (Atif et al. 2015). To address the non-response problem, the researcher should include some considerations as an integral part of a well-designed survey. The most effective measure is to pay close attention to the design of the questionnaire, and it should be pretested to improve its clarity and acceptability (Daniel 1975). Heneman and Patterson (1949) suggested that the nonresponse problem can be avoided or minimized significantly through proper training of interviewers.

\section{Descriptive Analysis}

Respondents' demographic profile

Descriptive statistics aim to summarize large sets of quantitative information in numerical form. It is normally used for analysis of demographic variables and an elaboration of the mean, standard deviation and correlation of the constructs. Two common presentations of descriptive statistics are the measure of central tendency (mean, median, and mode) and dispersion (the range, standard deviation, standard error and variance) (Fisher and Marshall 2009).

This transformation of data describes the basic characteristics of research such as the central tendency, distribution, variability (Quintana et al. 2015). However, according to Marshall and Jonker (2010), the descriptive statistics method may not be suitable to demonstrate causal analysis. This is the role of inferential analysis which would play a better role in helping to relate the sample to a larger group of population. In this research, we conducted demographic analysis against respondent profiles like age, gender, education level, experience of usage, course of study.

\section{Goodness-of-fit measures analysis}

Goodness-of-Fit (GoF) can be useful for a PLS multi-group analysis (PLS-MGA) when researchers compare the PLS-SEM results of different data groups for the same PLS path model (Henseler and Sarstedt 2012). Henseler, Hubona and Ray (2016) suggested that the overall goodness-of-fit of the model should be the starting point of model assessment. If the model does not fit the data, the data may contain more information than the model conveys.

\section{Data analysis and findings}


Results of the pilot test

Pilot testing is an informal, loosely structured set of procedures where the researcher explores, probes and tests many of the parameters of the study being planned (Bailey and Burch 2016). It is essential that the pilot phase of the study be informal enough to allow the testing of all the variables that would be included in the final project. The pilot test used 20 male participants $(56 \%)$ and 10 female participants $(44 \%)$. The majority of the participants $(36 \%)$ were within the age group of 18 to 24 years. Based on the result of the pilot testing, the reliability (internal consistency) for all the six constructs was reasonable and met the threshold of 0.70 as suggested by Hair et al. (2016). The Cronbach's alpha values for IoT Adoption were 0.811 (Perceived Benefits), 0.707 (Digital Mindset) and 0.884 (Technological Motivator); Technological Inhibitor, 0.920; Attitude, 0.927;

\section{Descriptive analysis}

Descriptive analysis is the essential transformation of data used to describe the basic characteristics of data gathered (Quintana et al., 2015). In this research, three analytical approaches were conducted in order to evaluate and understand the basic characteristics of the data, which covered (1) demographic profile of respondents; (2) construct analysis; and (3) correlation coefficient. The demographic data analysis results exhibit some typical characteristics of the Institution where $92.08 \%$ of the respondents are between 18 to 25 years old, which revealed that the majority of students were the millennial type and hence with more open behavior in understanding and accepting new technologies such as the Internet Of Things (IoT) products and services.

In addition, the majority of the students of the Institution were exposed to the IoT products and services for at least three years regardless of the area of expertise they had. In fact, most of the respondents were majors in Information Technology course than from Business courses. This indicated that the IoT has influences the daily living style of the students in general to a significant extent in Malaysia, which was a good sign in terms of enablement and promoting cutting edge technologies to the younger generations. High-tech products and services are seen as no longer a privilege to or limited to the computer literate user group with a strong technology background but more like a common trend and activity in anyone's daily life. This finding was also aligned to the Government's vision to become a highly digitalize and innovative nation in the near future.

\section{Correlational analysis}

In order to determine the direction and significance of the relationships between Perceived Benefit ("PE"), Digital Mindset ("DM"), Technological Motivator ("TM"), Technological Inhibitor ("TI") and Attitude ("AT") respectively towards IoT Adoption ("IA"), Pearson product-moment correlation analysis was conducted. As demonstrated in Table 1, the results indicated a large effect size $(\boldsymbol{r}>\mathbf{0 . 5 0})$ and positive association between PB, DM, TM,

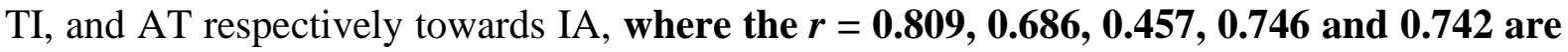
significant at the 0.01 level (2-tailed).

Table 1. Pearson Product-Moment Correlation Analysis Result



Perceived

Benefits

Digital Mindset $0.809^{* *}$

Yeo et al. 


\begin{tabular}{|c|c|c|c|c|c|c|}
\hline $\begin{array}{l}\text { Technological } \\
\text { Motivator }\end{array}$ & $0.686^{* *}$ & $0.682^{* *}$ & - & & & \\
\hline $\begin{array}{l}\text { Technological } \\
\text { Inhibitor }\end{array}$ & $0.457^{* *}$ & $0.487^{* *}$ & $0.447^{* * *}$ & - & & \\
\hline Attitude & $0.746^{* *}$ & $0.799^{* *}$ & $0.696^{* *}$ & $0.442^{* *}$ & - & \\
\hline IoT Adoption & $0.742^{* *}$ & $0.813^{* *}$ & $0.739^{* *}$ & $0.502^{* *}$ & $0.854^{* *}$ & - \\
\hline
\end{tabular}

\section{Assessment of measurement model}

\section{Reliability analysis}

Three assessments for reliability were conducted by using the PLS-SEM software, which cover the Cronbach's alpha, composite reliability and Dijkstra-Henseler's rho. Table 2 shows that the criteria of internal consistency for every construct employed in this research was achieved as all values in the three assessments are above 0.70 (Hair et al. 2019), indicating unidimensionality within each construct.

Table 2. Cronbach's Alpha Reliability Result

\begin{tabular}{lcccc}
\hline Construct & $\begin{array}{c}\text { Cronbach } \\
\text { s Alpha }\end{array}$ & $\begin{array}{c}\text { Composite } \\
\text { Reliability }\end{array}$ & $\begin{array}{c}\text { Dijkstra- } \\
\text { Henseler's } \\
\text { Rho }\end{array}$ & $\begin{array}{c}\text { Average Variance } \\
\text { Extracted (AVE) }\end{array}$ \\
\hline $\begin{array}{l}\text { Attitude } \\
\begin{array}{l}\text { Digital } \\
\text { Mindset }\end{array}\end{array}$ & 0.967 & 0.973 & 0.967 & 0.868 \\
$\begin{array}{l}\text { IoT Adoption } \\
\begin{array}{l}\text { Perceived } \\
\text { Benefits }\end{array}\end{array}$ & 0.923 & 0.946 & 0.925 & 0.813 \\
$\begin{array}{l}\text { Technological } \\
\text { Inhibitor }\end{array}$ & 0.973 & 0.978 & 0.973 & 0.861 \\
$\begin{array}{l}\text { Technological } \\
\text { Motivator }\end{array}$ & 0.918 & 0.977 & 0.97 & 0.893 \\
\hline
\end{tabular}

\section{Validity Analysis}

Validity refers to the extent to which the measurement procedure is measuring what it is intends to measure (and not something else) and whether it is being used and has interpreted the scores correctly (Christensen, Johnson and Turner 2015). SPSS was used for the EFA analysis. It consisted of KMO and Bartlett's Test of Sphericity. As proposed by Kaiser and Rice (1974), the KMO statistic should be higher than 0.50 in order to achieve the aptness of factor analysis. In this research, the KMO value was 0.953 , indicating that all items were appropriate as the measure of sampling adequacy is beyond the acceptable level of 0.50. In addition, the result of Bartlett's Test of Sphericity in this research was proven as significant $(p<0.001)$, suggesting that the correlation matrix was not an identity matrix, while the correlations between variables were significantly different from zero (Field 2013). The results of KMO and Bartlett's Test of Sphericity are presented in the following Table 3.

Table 3. Kaiser-Meyer-Olkin Measure (KMO) and Bartlett's Test

\begin{tabular}{|c|ll|}
\hline \multicolumn{2}{|l|}{ KMO and Bartlett's Test } \\
\hline \multicolumn{2}{|l|}{ Kaiser-Meyer-Olkin Measure of Sampling Adequacy. } & 0.953 \\
\hline \multirow{2}{*}{ Bartlett's Test of Sphericity } & Approx. Chi-Square & 9563.216 \\
\cline { 2 - 3 } & df & 528 \\
\hline
\end{tabular}


Convergent validity

The results of all factor loadings in the first-order measurement model (see Table 4), ranging from 0.858 to 0.954 , achieved beyond the threshold level of 0.708 (Hair et al. 2017). This indicated that all factors employed in the research were highly credible in their constructs measurement, where there are at least $50 \%$ of the variance shared to explain the latent construct measurement (Hair et al. 2017).

Table 4. Factor Loadings Analysis

\begin{tabular}{|c|c|c|c|c|c|c|}
\hline & Attitude & $\begin{array}{c}\text { Digital } \\
\text { Mindset }\end{array}$ & $\begin{array}{c}\text { IoT } \\
\text { Adoption }\end{array}$ & $\begin{array}{c}\text { Perceived } \\
\text { Benefits }\end{array}$ & $\begin{array}{c}\text { Technological } \\
\text { Inhibitor }\end{array}$ & $\begin{array}{c}\text { Technological } \\
\text { Motivator }\end{array}$ \\
\hline AT1 & 0.924 & & & & & \\
\hline AT2 & 0.927 & & & & & \\
\hline AT3 & 0.933 & & & & & \\
\hline AT4 & 0.926 & & & & & \\
\hline AT5 & 0.935 & & & & & \\
\hline AT6 & 0.914 & & & & & \\
\hline DM5 & & 0.866 & & & & \\
\hline DM6 & & 0.899 & & & & \\
\hline DM7 & & 0.924 & & & & \\
\hline DM8 & & 0.917 & & & & \\
\hline IA 1 & & & 0.907 & & & \\
\hline IA2 & & & 0.936 & & & \\
\hline IA3 & & & 0.913 & & & \\
\hline IA4 & & & 0.929 & & & \\
\hline IA5 & & & 0.944 & & & \\
\hline IA6 & & & 0.929 & & & \\
\hline IA7 & & & 0.937 & & & \\
\hline PB1 & & & & 0.931 & & \\
\hline PB2 & & & & 0.951 & & \\
\hline PB3 & & & & 0.938 & & \\
\hline PB4 & & & & 0.954 & & \\
\hline PB5 & & & & 0.949 & & \\
\hline TI4 & & & & & 0.858 & \\
\hline TI5 & & & & & 0.890 & \\
\hline TI6 & & & & & 0.934 & \\
\hline TI7 & & & & & 0.897 & \\
\hline TM1 & & & & & & 0.944 \\
\hline TM2 & & & & & & 0.954 \\
\hline TM3 & & & & & & 0.931 \\
\hline TM4 & & & & & & 0.881 \\
\hline TM5 & & & & & & 0.929 \\
\hline reo et al. & & & & & & 79 \\
\hline
\end{tabular}


The AVE value for each of the constructs (refer to Table 5), ranging from 0.801 to 0.893 , was above the minimum cut-off value of 0.50 (Hair et al. 2017; Hair, Ringle and Sarstedt 2013). It was evident, therefore, at least $61 \%$ of variance was explained by the factors to their respective constructs. As the results show below, the first-order measurement model's factor loadings and AVE results proved the uni-dimensionality. The result indicated that the convergent validity of factors had been fulfilled.

Table 5. Average Variance Extracted Result (AVE)

\begin{tabular}{lcccc}
\hline Construct & $\begin{array}{c}\text { Cronbach's } \\
\text { Alpha }\end{array}$ & $\begin{array}{c}\text { Composite } \\
\text { Reliability }\end{array}$ & $\begin{array}{c}\text { Dijkstra- } \\
\text { Henseler's Rho }\end{array}$ & $\begin{array}{c}\text { Average Variance } \\
\text { Extracted (AVE) }\end{array}$ \\
\hline Attitude & 0.967 & 0.973 & 0.967 & 0.868 \\
$\begin{array}{l}\text { Digital Mindset } \\
\begin{array}{l}\text { IoT Adoption } \\
\text { Perceived Benefits }\end{array}\end{array}$ & 0.923 & 0.946 & 0.925 & 0.813 \\
$\begin{array}{l}\text { Technological } \\
\text { Inhibitor }\end{array}$ & 0.973 & 0.978 & 0.973 & 0.861 \\
$\begin{array}{l}\text { Technological } \\
\text { Motivator }\end{array}$ & 0.97 & 0.977 & 0.97 & 0.893 \\
\hline
\end{tabular}

Discriminant validity (vertical collinearity)

As per suggestion of Ramayah et al. (2016), the Fornell-Larcker's criterion, cross-loading criterion and HTMT assessments are performed to examine the discriminant validity of the first-order measurement model. Table 6 indicates that the off-diagonal inter-correlation values of constructs are smaller than the values of square root of AVE, signifying that the latent construct measurement was totally discriminant with each other (Hair et al. 2017).

Table 6. Fornell-Larcker's Criterion Result

\begin{tabular}{lcccccc}
\hline & Attitude & $\begin{array}{c}\text { Digital } \\
\text { Mindset }\end{array}$ & $\begin{array}{c}\text { IoT } \\
\text { Adoption }\end{array}$ & $\begin{array}{c}\text { Perceived } \\
\text { Benefits }\end{array}$ & $\begin{array}{c}\text { Technology } \\
\text { Inhibitor }\end{array}$ & $\begin{array}{c}\text { Technology } \\
\text { Motivator }\end{array}$ \\
\hline $\begin{array}{l}\text { Attitude } \\
\begin{array}{l}\text { Digital } \\
\text { Mindset }\end{array}\end{array}$ & 0.926 & 0.801 & 0.902 & & & \\
$\begin{array}{l}\text { IoT Adoption } \\
\text { Perceived }\end{array}$ & 0.854 & 0.814 & 0.928 & & & \\
$\begin{array}{l}\text { Benefits } \\
\text { Technology }\end{array}$ & 0.746 & 0.81 & 0.743 & 0.945 & & \\
$\begin{array}{l}\text { Inhibitor } \\
\text { Technology }\end{array}$ & 0.452 & 0.496 & 0.51 & 0.464 & 0.895 & \\
Motivator & 0.697 & 0.685 & 0.741 & 0.686 & 0.453 & 0.926 \\
\hline
\end{tabular}

Table 7 below translates the results of discriminant analysis under the cross-loading method. The results validate that all the indicator loadings were clearly separated across the latent variables, as the loadings are high on their own constructs whilst low at the other constructs (Chin 1998). 
Table 7. Cross Loadings Result

\begin{tabular}{|c|c|c|c|c|c|c|}
\hline & Attitude & $\begin{array}{c}\text { Digital } \\
\text { Mindset }\end{array}$ & $\begin{array}{c}\text { IoT } \\
\text { Adoption }\end{array}$ & $\begin{array}{c}\text { Perceived } \\
\text { Benefits }\end{array}$ & $\begin{array}{c}\text { Technological } \\
\text { Inhibitor }\end{array}$ & $\begin{array}{c}\text { Technological } \\
\text { Motivator }\end{array}$ \\
\hline AT1 & 0.924 & 0.726 & 0.771 & 0.667 & 0.435 & 0.644 \\
\hline AT2 & 0.927 & 0.753 & 0.776 & 0.704 & 0.425 & 0.635 \\
\hline AT3 & 0.933 & 0.785 & 0.816 & 0.712 & 0.433 & 0.678 \\
\hline AT4 & 0.926 & 0.755 & 0.795 & 0.667 & 0.421 & 0.642 \\
\hline AT5 & 0.935 & 0.725 & 0.785 & 0.692 & 0.398 & 0.626 \\
\hline AT6 & 0.914 & 0.706 & 0.804 & 0.704 & 0.397 & 0.644 \\
\hline DM5 & 0.657 & 0.866 & 0.718 & 0.643 & 0.441 & 0.571 \\
\hline DM6 & 0.714 & 0.899 & 0.69 & 0.749 & 0.431 & 0.567 \\
\hline DM7 & 0.724 & 0.924 & 0.747 & 0.755 & 0.445 & 0.634 \\
\hline DM8 & 0.789 & 0.917 & 0.776 & 0.773 & 0.47 & 0.69 \\
\hline IA1 & 0.778 & 0.731 & 0.907 & 0.637 & 0.413 & 0.66 \\
\hline IA2 & 0.818 & 0.759 & 0.936 & 0.685 & 0.436 & 0.73 \\
\hline IA3 & 0.777 & 0.727 & 0.913 & 0.676 & 0.469 & 0.713 \\
\hline IA4 & 0.779 & 0.757 & 0.929 & 0.688 & 0.457 & 0.659 \\
\hline IA5 & 0.825 & 0.777 & 0.944 & 0.703 & 0.485 & 0.69 \\
\hline IA6 & 0.778 & 0.757 & 0.929 & 0.708 & 0.525 & 0.666 \\
\hline IA7 & 0.793 & 0.779 & 0.937 & 0.725 & 0.529 & 0.69 \\
\hline PB1 & 0.706 & 0.762 & 0.712 & 0.931 & 0.399 & 0.624 \\
\hline PB2 & 0.691 & 0.769 & 0.699 & 0.951 & 0.459 & 0.659 \\
\hline PB3 & 0.696 & 0.759 & 0.701 & 0.938 & 0.435 & 0.665 \\
\hline PB4 & 0.691 & 0.758 & 0.69 & 0.954 & 0.45 & 0.634 \\
\hline PB5 & 0.74 & 0.779 & 0.705 & 0.949 & 0.449 & 0.661 \\
\hline TI4 & 0.31 & 0.359 & 0.374 & 0.368 & 0.858 & 0.338 \\
\hline TI5 & 0.352 & 0.387 & 0.392 & 0.336 & 0.89 & 0.366 \\
\hline TI6 & 0.466 & 0.504 & 0.493 & 0.455 & 0.934 & 0.44 \\
\hline TI7 & 0.453 & 0.493 & 0.532 & 0.474 & 0.897 & 0.454 \\
\hline TM1 & 0.658 & 0.641 & 0.65 & 0.63 & 0.445 & 0.944 \\
\hline TM2 & 0.682 & 0.679 & 0.72 & 0.682 & 0.468 & 0.954 \\
\hline TM3 & 0.632 & 0.62 & 0.652 & 0.628 & 0.433 & 0.931 \\
\hline TM4 & 0.572 & 0.6 & 0.683 & 0.597 & 0.345 & 0.881 \\
\hline TM5 & 0.68 & 0.632 & 0.702 & 0.64 & 0.438 & 0.929 \\
\hline TM6 & 0.625 & 0.621 & 0.673 & 0.621 & 0.393 & 0.93 \\
\hline TM7 & 0.661 & 0.64 & 0.713 & 0.646 & 0.414 & 0.911 \\
\hline
\end{tabular}

By implementing the HTMT discriminant method, the results (refer to Table 8) indicated that the correlations of latent variables were highly significant (all $p$-values $<0.001$ ) and most were below 0.85, which is in line with the recommendation of Kline (2016) except IoT Adoption variable with the HTML value of 0.857 , which was slightly higher than the threshold value of 0.85. As the other two tests (Fornell-Larcker, Cross Loading) had already fulfilled the rule of thumb (Kline 2016), the discriminant validity was achieved even though the correlation between IoT Adoption to Attitude and Digital Mindset were slight higher above $0.85(0.880$ and 0.857 respectively). Thus, it can be concluded that the latent measurement constructs were clearly discriminant with each other.

Table 8. HTMT Discriminant Assessment Result 


\begin{tabular}{|l|c|l|l|l|l|l|} 
& Attitude & $\begin{array}{l}\text { Digital } \\
\text { Mindset }\end{array}$ & $\begin{array}{l}\text { IoT } \\
\text { Adoption }\end{array}$ & $\begin{array}{l}\text { Perceived } \\
\text { Benefits }\end{array}$ & $\begin{array}{l}\text { Technological } \\
\text { Inhibitor }\end{array}$ & $\begin{array}{l}\text { Technologic } \\
\text { al Motivator }\end{array}$ \\
\hline Attitude & & & & & & \\
\hline $\begin{array}{l}\text { Digital } \\
\text { Mindset }\end{array}$ & $0.846^{* *}$ & & & & & \\
\hline IoT Adoption & 0.88 & 0.857 & & & & \\
\hline $\begin{array}{l}\text { Perceived } \\
\text { Benefits }\end{array}$ & $0.77 * *$ & 0.855 & $0.764 * *$ & & & \\
\hline $\begin{array}{l}\text { Technological } \\
\text { Inhibitor }\end{array}$ & $0.468^{* *}$ & $0.528^{* *}$ & $0.529 * *$ & $0.483 * *$ & & \\
\hline $\begin{array}{l}\text { Technological } \\
\text { Motivator }\end{array}$ & $0.717 * *$ & $0.72 * *$ & $0.76^{* *}$ & $0.706^{* *}$ & $0.472^{* *}$ & \\
\hline
\end{tabular}

Assessment of Model Fit

Based on the result of Table 9, the SRMR values are 0.035 and 0.220 for the saturated model and estimated Model respectively. According to $\mathrm{Hu}$ and Bentler (1999), a value of less than 0.10 or of 0.08 is considered a good fit. Therefore, this indicated that the model had a considerably good fit for the saturated model but not the estimated model. In this case, this also gave a message that the data collected from the respondents could have contained more information than the model conveyed perhaps due to the advancement of the Internet Of Things (IoT) topic in the educational industry or, that the understanding of coverage of IoT products and services could be further beyond the boundary of this research.

Table 9. Model Fit Analysis

\begin{tabular}{lc}
\hline Models & $\begin{array}{c}\text { Standard Root Mean Square } \\
\text { Residual (SRMR) }\end{array}$ \\
\hline Saturated Model & 0.035 \\
Estimated Model & 0.22 \\
\hline
\end{tabular}

Assessment of structural model

According to the Ramayah et al. (2016), there are 6 steps to assess the structural model in PLSSEM. It consists of: (1) the assessment for collinearity issues, (2) assessment the significance and relevance of the structure model relationships, (3) assessment of the level of R square, (4) assessment of the Effect Size (f square), (5) assessment of Predictive Relevance (Q square) and the optional (6) effective size of q square.

Assessment of Significant and Relevance of the Structural Model relationships (Path Coefficient) 


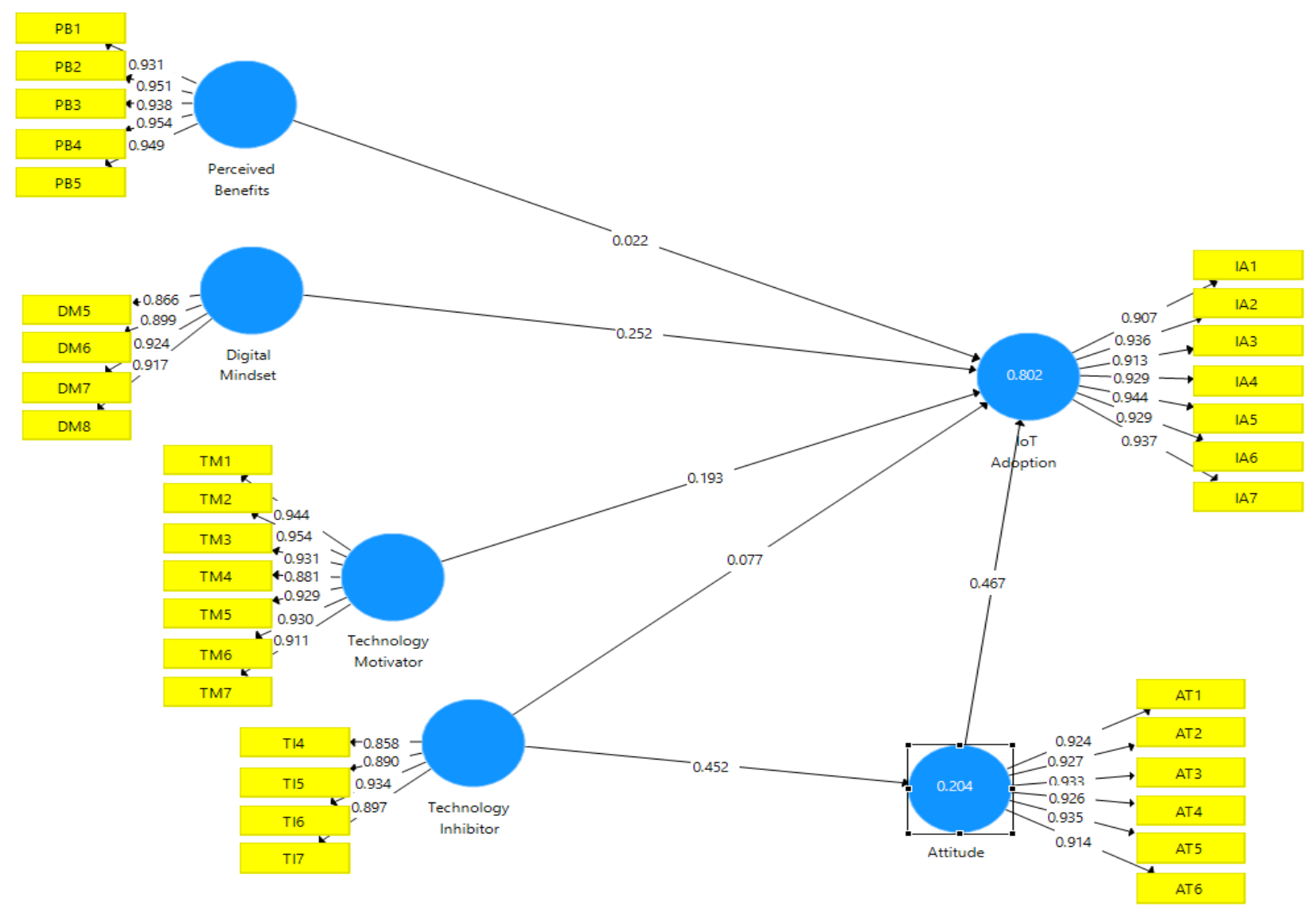

Figure 2. Path Analysis Model (PLS-SEM)

By referring to the results in Table 10 and Figure 2, the relative importance of the exogenous constructs in predicting the dependent construct (IoT Adoption), it is evident that attitude (AT $=0.467)$ is the most important predictor, followed by digital mindset $(\mathrm{DM}=0.252)$, technology motivator $(\mathrm{TM}=0.193)$, technology inhibitor $(\mathrm{TI}=0.077)$ and finally the perceived benefits $(\mathrm{PB}=0.022)$.

In this research study, there were six direct hypotheses developed between the constructs. In order to evaluate the significance level, the t-statistics for all paths were generated using a bootstrapping function (Chin 1998). As revealed in Table 11, all five relationships had a t-value greater than 1.645 (except Perceived Benefits $->$ IoT Adoption $=0.283$ ) thus significant at 0.05 level of significance. Typically, the predictors of Attitude $(\beta=0.467, t=3.67, p<0.01)$, Digital Mindset $(\beta=0.252, \mathrm{t}=2.500, \mathrm{p}<0.01)$ and Technology Motivator $(\beta=0.193, \mathrm{t}=2.837, \mathrm{p}<$ $0.01)$ were positively related on IoT Adoption whereas Technology Inhibitor $(\beta=0.077$, $\mathrm{t}=1.667, \mathrm{p}<0.05)$ was negatively associated with the adoption of Internet of Things. As the result indicated, H2, H3, H4 and H5(a) were supported. Furthermore, the $R$ square value of 0.802 was above the 0.26 value proposed by Cohen (1988) which translates into a substantial model.

Table 10. Path Coefficients Analysis Result (Means, STDEV, T-Values, P-Values)

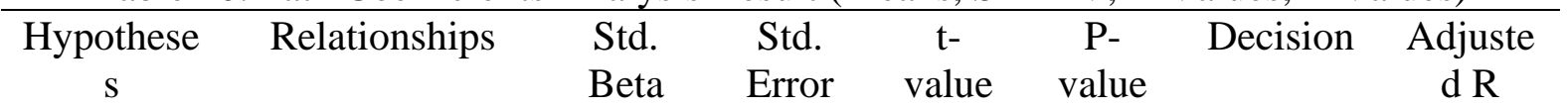
square 


\begin{tabular}{|c|c|c|c|c|c|c|c|}
\hline $\mathrm{H} 1$ & $\begin{array}{l}\text { Perceived } \\
\text { Benefits -> IoT } \\
\text { Adoption }\end{array}$ & 0.022 & 0.078 & 0.283 & 0.389 & $\begin{array}{c}\text { Not } \\
\text { supporte } \\
\text { d }\end{array}$ & \\
\hline $\mathrm{H} 2$ & $\begin{array}{l}\text { Digital Mindset } \\
\text {-> Iot Adoption }\end{array}$ & 0.252 & 0.101 & 2.500 & 0.006 & $\begin{array}{c}\text { Supporte } \\
\text { d }\end{array}$ & \\
\hline H3 & $\begin{array}{l}\text { Technological } \\
\text { Motivator -> IoT } \\
\text { Adoption }\end{array}$ & 0.193 & 0.068 & 2.837 & 0.002 & $\begin{array}{c}\text { Supporte } \\
\text { d }\end{array}$ & 0.797 \\
\hline H4 & $\begin{array}{l}\text { Technological } \\
\text { Inhibitor -> Iot } \\
\text { Adoption }\end{array}$ & 0.077 & 0.046 & 1.667 & 0.048 & $\begin{array}{c}\text { Supporte } \\
\mathrm{d}\end{array}$ & \\
\hline H5(a) & $\begin{array}{l}\text { Attitude } \\
\text {-> Iot Adoption }\end{array}$ & 0.467 & 0.127 & 3.679 & 0.000 & $\begin{array}{c}\text { Supporte } \\
\text { d }\end{array}$ & \\
\hline $\mathrm{H} 5$ (b) & $\begin{array}{l}\text { Technological } \\
\text { Inhibitor } \\
\text { Attutude }\end{array}$ & 0.452 & 0.077 & 5.841 & 0.000 & $\begin{array}{c}\text { Supporte } \\
\text { d }\end{array}$ & 0.200 \\
\hline
\end{tabular}

As stated above, one path coefficient, Perceived Benefits to IoT Adoption $(\beta=0.022, t=0.283$, $\mathrm{p}=0.389$ ) was proved not significant at the 0.05 level of significance since its' observed tvalue of 0.283 was below the recommended value of 1.96 and p-value of 0.389 was higher than 0.05

(Hair et al. 2017). Therefore, H1 was not supported.

Next, the result of the effect of Technology Inhibitor on Attitude indicated that Technology Inhibitor $(\mathrm{B}=0.452, \mathrm{t}=5.841, \mathrm{p}<0.01)$ was also negatively related to attitude, explaining $20.4 \%$ of variance in attitude. This result appeared to support the $\mathrm{H} \mathrm{5(b)}$ of this research study.

Table 11. Path Coefficients Analysis Result (Confidence Intervals)

\begin{tabular}{llccc}
\hline Hypotheses & \multicolumn{1}{c}{ Relationships } & $\begin{array}{c}\text { Std. } \\
\text { Beta }\end{array}$ & $\mathbf{5 \%}$ & $\mathbf{9 5 \%}$ \\
\hline H1 & Perceived Benefits -> IoT Adoption & 0.022 & -0.099 & 0.153 \\
H2 & $\begin{array}{l}\text { Digital Mindset -> Iot Adoption } \\
\text { Technological Motivator -> IoT }\end{array}$ & 0.252 & 0.082 & 0.413 \\
H3 & Adoption & 0.193 & 0.071 & 0.29 \\
H4 & Technological Inhibitor -> Iot Adoption & 0.077 & 0.005 & 0.156 \\
H5(a) & Attitude -> Iot Adoption & 0.467 & 0.28 & 0.698 \\
H5(b) & Technological Inhibitor -> Attutude & 0.452 & 0.329 & 0.574 \\
\hline
\end{tabular}

Interval estimates are preferred to point estimates because confidence intervals indicate (a) the precision of the estimate and (b) the uncertainty of the estimate especially if a bootstrapping technique is used. Therefore, in this research study, the confidence interval is taken into consideration in the measurement as well. Based on the results obtained in Table 4.26, 0 is not a straddle between the confidence intervals bias results (except Perceived Benefits to IoT Adoption), but rather it means that there is a significant result.

\section{Assessment of mediation}

There was one mediation hypotheses (H5 (c)) formulated in this research with the aim to investigate the indirect effects of Attitudes (AT) on the relationships between Technological 
Inhibitor (TI) with IoT Adoption (IA). The PLS-SEM's bootstrapping procedure with 5,000 bootstrap samples was used for mediation analysis as per the suggestion by Hair et al. (2017) and Iacobucci, Saldanha and Deng (2007). The purpose was to see how Attitudes mediates the relationship between the predictors (Technological Inhibitor) and IoT Adoption.

The bootstrapping analysis showed that the indirect effects $(B=0.211)$ was significant with $t-$ value of 3.030. The indirect effect \% Boot XX Bias Corrected: $[\mathrm{LL}=0.089, \mathrm{UL}=0.363$ ] does not straddle a 0 in between, indicating that there is mediation (Preacher and Hayes 2004). Based on the result observed, we concluded that the mediation effect was statistically significant at tvalues $>1.96$ and $\mathrm{p}$-value $<0.005$. This finding was aligned to former research studies (Hsu and Lin 2016; Yoon 2002) that the technological inhibitor such as trust, concern of information privacy may influence adoption intention behavior indirectly via attitude.

The result of mediation analysis is presented in Table 12 .

Table 12. Mediation Analysis Result

\begin{tabular}{llllllll}
\hline No. & Relationship & $\begin{array}{l}\text { Std. } \\
\text { Beta }\end{array}$ & $\begin{array}{l}\text { Std. } \\
\text { Error }\end{array}$ & t-Value & $\begin{array}{l}\text { Confidence } \\
\text { Interval } \\
\text { (BC) }\end{array}$ & $\begin{array}{l}\text { P- } \\
\text { Value }\end{array}$ & Decision \\
\hline 1 & $\begin{array}{l}\text { Technological } \\
\text { Inhibitor }\end{array}$ & 0.211 & 0.07 & 3.030 & $\begin{array}{l}\text { LL }=0.089, \\
\text { UL }=0.363\end{array}$ & 0.003 & Supported \\
& & & & & \\
& $\rightarrow$ Attitude \\
-> IoT Adoption & & & & & \\
\hline$* * \mathrm{p}<0.05$, BC = Bias Corrected, UL = Upper Level, LL = Lower Level &
\end{tabular}

\section{Discussion and Conclusion}

There were seven hypotheses developed in this research, where the outcomes of H1 to H5(a) reflected the research question 1, 2 and 3 respectively. Table 13 summarizes the result of the tested hypotheses in the research study.

Based on the results, attitude plays the greatest influence with regard to decision of adopting any IoT products or services. Apart from the direct effect towards IoT adoption, attitude was found to mediate the impact of technological inhibitor to the IoT adoption intention. This lends support to some of the past seminal work (Karahoca, Karahoca and Aksöz 2018; Carter and Yeo 2016; Jahanmir and Cavadas 2018). Other researchers (Veryzer 2003; Hawk et al. 2008; Schwab 2016) also have contended that people have embraced the new technological trend and mentally prepared for the future change. In our study, interestingly, digital mindset was also found to be a salient factor that explained user's adoption intention behavior on IoT technologies. Perceived benefits, however, imposed an insignificant direct effect whereas technological inhibitor perspective affected the IoT adoption intention through attitude factor. This was unexpected probably due to the fact that IoT is a relatively new topic to the respondents in the high education institution. The respondents might not even be aware that they are 'part' of the IoT ecosystem and have already leveraging the conveniences offered by IoT and enjoying the benefits brought by the technology in their daily life. Although technological inhibitor did not seem to impose a strong direct effect toward user's adoption intention, it had an indirect effect through attitude, on intention to use the IoT products and services. Another important result was the significant correlation between attitude and digital mindset. While explaining the impact of technological motivator on IoT adoption there was a significant direct effect on females, whereas it was found that there was no significant direct 
effect on male respondents. It was observed that for males, digital mindset was a more significant factor to explain IoT adoption behavior compared to females.

Table 13. Summary of the tested Hypotheses

\begin{tabular}{|c|c|c|c|c|}
\hline Hypotheses & Relationships & Std Beta & t-value & Decision \\
\hline H1 & $\begin{array}{l}\text { Perceived Benefits is positively } \\
\text { associated with the adoption of } \\
\text { Internet of Things. }\end{array}$ & 0.022 & 0.283 & $\begin{array}{c}\text { Not } \\
\text { supported }\end{array}$ \\
\hline H2 & $\begin{array}{l}\text { Digital mindset is positively } \\
\text { associated with the adoption of } \\
\text { Internet of Things. }\end{array}$ & 0.252 & $2.500 * *$ & Supported \\
\hline H3 & $\begin{array}{l}\text { Technological motivator has a } \\
\text { significant positive effect to the } \\
\text { adoption of Internet of Things. }\end{array}$ & 0.193 & $2.837 * *$ & Supported \\
\hline H4 & $\begin{array}{l}\text { Technological inhibitor is negatively } \\
\text { associated with the adoption of } \\
\text { Internet of Things. }\end{array}$ & 0.077 & $1.667 * *$ & Supported \\
\hline H5(a) & $\begin{array}{l}\text { Attitude is positively associated with } \\
\text { the adoption of Internet of Things. }\end{array}$ & 0.467 & $3.679 * *$ & Supported \\
\hline H5(b) & $\begin{array}{l}\text { Technological inhibitor is negatively } \\
\text { associated with the attitude. }\end{array}$ & 0.452 & $5.841 * *$ & Supported \\
\hline H5(c) & $\begin{array}{l}\text { Attitude mediates the relationship } \\
\text { between technological inhibitor and } \\
\text { adoption of Internet of Things. }\end{array}$ & 0.211 & $3.030 * *$ & Supported \\
\hline
\end{tabular}

\section{Theoretical Implications}

This study extends the landscape of past research (e.g: Gao and Bai 2014; Hsu and Tsou 2011) done to explore further the human culture and mindset (digital mindset) and technological elements (motivator and barrier) with the aim to examine the determinants of Internet of Things adoption in the educational institution in Malaysia. Generation $\mathrm{Z}$ (students in this case), is the key to next generations in the continuing promotion and adoption of new technology such as the Internet of Things. Thus, it is important to understand the latest developments in the education sector, which is one of the fundamentals to develop the adoption behavior, or vice versa. This research has been carried out to fill that gap by analysing the various interrelated factors that influence the Internet of Things (IoT) adoption in the Educational Institution.

The results can be applied to the individual level to a person with a digital sense who would be more open to adopt the IoT products and services compared to those who could be more reluctant to grow with the digital transformation trend. This group of respondents enjoys the benefits, conveniences and values as a result of the emerging technologies. Findings also suggest that all individuals regardless of gender, age, education level tend to pay more attention to attitude and digital mindset in their adoption of IoT products and services in an educational environment. Contrary to the past findings (e.g: Hsu and Lin 2016, Park et al. 2017), our research findings provides further evidence that attitude and digital mindset build within the individual are crucial elements to be considered in justifying the adoption behavior to the IoT products and services. In order to succeed in adoption of the |IoT, a macro environment that promotes the right innovation attitude and mindset are essential. The findings tends to corroborate with the empirical results of Bienhaus and Haddud (2018); wherein employee were 
receptive to the digitalisation of procurement and supply chains that contributed to the company performance.

It was worth noting that previous findings (e.g: Heinis et al. 2018) on IoT application adoption are a common motivator. However there were also inhibitors which hindered the development of IoT applications such as business and organisational inhibitors, which tended to be more challenging. Although they have an essential impact on the success of innovation in IoT applications. Hence, the adoption of IoT regardless of which sector or industry seemingly presented a double-sword outcome (motivator and inhibitor) which further reinforced our current findings in an educational context.

\section{Practical Implications}

From a practical viewpoint, the research findings have managerial implications to both the stakeholders at the leadership and strategic level. It is believed that a leader who has a digital mindset would be more supportive to empower the transfer of digital knowledge and futureproof students in preparation for the digital revolution in the coming decades. With the support of Internet of Things products and services such as Advance Analytics, helps to understand user behavior and segment audiences to offer better engagement and experience with relevant, personalised content, as well as for the user to make data-driven decisions. This helps to analyse the driver and barrier factors which can influence the adoption rate of the Internet of Things, for instance, the Attitude, Digital Mindset, Perception of benefits behavior, the Technological Motivator as well as the Technological inhibitors. In today's competitive situation even in the educational line, offering innovative, connected applications fast and economically can be extremely challenging (Dreamforce, 2019). In the classroom, for example, the use of IoT through the medium of massive open online courses (MOOCs), by which top lecturers at elite institutions can now be watched, and their courses taken, by thousands of eager students, takes some time to develop. The average enterprise has more than 900 systems and the ability to integrate these systems quickly are crucial in the rapidly moving environment. The same situation is applicable to the educational environment. Through smart devices, it could enable academic staff like lecturers and tutors to automate some of the manual tasks such as lesson planning, schedule adjustment and notification to others, and many more. So, whilst time consuming tasks can be taken over by smart devices, tutors can focus on more on value added activities like teaching, research and collaboration with other institutions.

On the other hand, this research also aimed to study how the Internet of Things (IoT), in an educational institution, is changing the learning approach and behavior of students in practicing and sustaining an innovation culture to enable it to develop and maintain a competitive advantage against other institutions. Emerging technologies such as the Internet of Things (IoT), Artificial Intelligence (AI) and cognitive computing, augmented, virtual and mixed reality (R+) and Blockchain for example are expected to improve study and life quality (Schwab 2016) and to assist higher education students to have a better educational experience. Innovation in education is observed in many places. Ridley (2015) found that technology is about to change education radically and this is happening even in the developing countries like Kenya. The Bridge International Academies group is able to run two hundred low-cost schools using a scripted syllabus delivered by tablet computer, which is also being used as a monitor device to track and record the teaching. Similarly, Khan Academy offers more than four thousand short videos of high-quality private tuition that can be used by anyone, anywhere, in any topic. The presence and adoption of IoT products and services, allows institutions to change and innovate faster by making integration easier for application, data and other devices and so helps to build 
an innovative digital learning ecosystem with connected application among staff, students and the commercial world.

From the organisational, as well as the individual perspective, by understanding the motivating and inhibition factors that could encourage the adoption decision towards IoT products and services, it could create value for IoT technology and the Industrial 4.0 ecosystem including Big Data, Artificial Intelligent (AI), Cloud technology, Machine Learning (ML) and Robotic Process Automation (RPA). Likewise, to create the condition to encourage acceptance of IoT products and services, industrial players in the market can organise relevant campaigns and invite the higher education institutions to participate and learn together. This could fill the gap in knowledge and skills through partnerships with education institutions and help to promote and create an innovation culture and digital mindsets to the new generations via more education/business interactions. Apart from building the relationship, building right attitudes, increasing the level of trust and building the required competency to support new technology are essential. To facilitate this, the providers must ensure the internal capability to keep personal data secure from unauthorized access, provide honest and trustworthy information to both existing and potential new users, all the time.

Finally, yet importantly, this research conceptual model could be used by those who are interested to explore further into the IoT technology area as a reference to understand the most influencing factors in the education environment. The Internet of Things (IoT) technology is shaping the future of living style for humans; evolving the way educational institutions operate, transforming the abilities of lecturers to deliver personalised teaching experiences for students like never before and of course, the capability of students to leverage technology to improve their learning experiences. Leaders in the organisation are using these tools and data to drive intelligent decision-making, working better together, and leading the evolution of operations in the education ecosystem. As such, it is now the best time to rethink how the higher education system works to align with policy maker's strategies and goals and let education evolve. Academics and students in the higher education sector are expected to be in a leading role to drive the innovation and development of IoT applications, products and services into the next decades.

\section{Research Limitations and Recommendations}

Although the research findings reported here explore and discover some new insights to researchers, there are some limitations, which can be addressed in the future. Firstly, due to the fact that this research focused on the study of the impact of behavioral and technological attributes on IoT adoption intention, other motivators such as incentives or influence from the authority (leaders, top management, government and policy maker) are not evaluated. Environmental conditions such as the readiness of the infrastructure, the commonality of the usage in the social group remain pressing and could be areas for future research.

Secondly, the study mainly involved those respondents who are in the educational environment. Therefore, the study does not sufficiently cover those working personnel from the commercial world, especially those who have experiences that are more practical in day-to-day applications. Lastly, the adoption of a convenience sampling technique may have limited the audiences that represents the intended population (Zikmund et al. 2010). Consequently, the research result may not be as generalizable as could be expected. It is suggested, therefore, to utilize probability-sampling technique to assess IoT adoption intention in the future research so that the result could be more representative of the general population of users. 
Finally, it is recommended to extend the respondents to commercial environment users who have heavy implementation of IoT in their daily operational and production activities. The target audiences can be from specific industries such as retail, financial institutes, life science and healthcare, or entertainment where IoT could, or is, seriously impacting. For instance, insights gained from data analysis will drive the digital disruption of many of these industries, evolve the current business processes and facilitate real-time decision-making for politicians and authorities alike.

\section{References}

Aldowah, H., Rehman, S. U., Ghazal, S., \& Umar, I. N. (2017, January). Internet of Things in higher education: a study on future learning. Journal of Physics: Conference Series, 892(1), 1-10.

AlHogail, A. (2018). Improving IoT technology adoption through improving consumer trust. Technologies, 6(3), 64-80.

Alsaadi, E., \& Tubaishat, A. (2015). Internet of things: features, challenges, and vulnerabilities. International Journal of Advanced Computer Science and Information Technology, 4(1), $1-13$.

Atif, A., Richards, D., Busch, P., \& Bilgin, A. (2015). Assuring graduate competency: a technology acceptance model for course guide tools. Journal of Computing in Higher Education, 27(2), 94-113.

Atzori, L., Iera, A., \& Morabito, G. (2010). The internet of things: A survey. Computer Networks, 54(15), 2787-2805.

Bailey, J. S., \& Burch, M.R. (2016). Ethics for Behavior Analysts, $3^{\text {rd }}$ ed. United States: Routledge.

Bass, B. M., Avolio, B. J., Jung, D. I., \& Berson, Y. (2003). Predicting unit performance by assessing transformational and transactional leadership. Journal of applied psychology, $88(2), 207-218$.

Benke, V. (2013). The Digital Mindset: A theoretical discussion. (Master Thesis). Retrieved from http://projekter.aau.dk/projekter/files/77247472/Vivienne_Benke_Masters_thesis.pdf

Bienhaus, F., \& Haddud, A. (2018). Procurement 4.0: factors influencing the digitisation of procurement and supply chains. Business Process Management Journal, 24(4), 965-984.

Boos, D., Guenter, H., Grote, G., \& Kinder, K. (2012). Controllable accountabilities: The Internet of Things and its challenges for organisations. Behaviour \& Information Technology, 32(5), 449-467.

Buchanan, E. A., \& Hvizdak, E. E. (2009). Online survey tools: Ethical and methodological concerns of human research ethics committees. Journal of Empirical Research on Human Research Ethics, 4(2), 37-48.

Carter, S., \& Yeo, A. C. M. (2016). Mobile apps usage by Malaysian business undergraduates and postgraduates. Internet Research., 26(3), 733-757.

Cegarra-Navarro, J. G., Garcia-Perez, A., \& Moreno-Cegarra, J. L. (2014). Technology knowledge and governance: Empowering citizen engagement and participation. Government Information Quarterly, 31(4), 660-668.

Chen, L, Gillenson, M. L., \& Sherrell, D. L. (2002). Enticing online consumers: an extended technology acceptance perspective. Information \& management, 39(8), 705-719. 
Chin, W. W. (1998). The partial least squares approach for structural equation modeling, $1^{\text {st }}$ ed., Hillsdale : Lawrence Erlbaum Associates Publishers.

Chin, W. W., Marcolin, B. L., \& Newsted, P. R. (2003). A partial least squares latent variable modeling approach for measuring interaction effects: Results from a Monte Carlo simulation study and an electronic-mail emotion/adoption study. Information systems research, 14(2), 189-217.

Choi, J., \& Kim, S. (2016). Is the smartwatch an IT product or a fashion product? A study on factors affecting the intention to use smartwatches. Computers in Human Behavior, 63, 777-786.

Christensen, L. B., Johnson, B., Turner, L. A., \& Christensen, L. B. (2015). Research Methods, Design, and Analysis, $12^{\text {th }}$ ed. London: Pearson.

Cohen, J. (1988). Statistical power analysis for the behavioral sciences, $2^{\text {nd }}$ ed. Hillsdale: Lawrence Earlbaum Associates.

Cozby, P.C, \& Bates, S.C. (2012). Methods in behavioral research, $11^{\text {th }}$ ed. Boston: McGraw Hill Higher Education.

Creswell, J. W., \& Creswell, J. D. (2003). Research design: Qualitative, quantitative, and mixed methods approaches, $2^{\text {nd }}$ ed. Thousand Oaks: Sage publications.

Creswell, J.W. (2014). Research Design: Qualitative, quantitative and Mixed Methods Approaches, $4^{\text {th }}$ ed. Thousand Oaks: SAGE Publications.

Daniel, W. W. (1975). Nonresponse in sociological surveys: A review of some methods for handling the problem. Sociological Methods \& Research, 3(3), 291-307.

Davis, F. D. (1989). Perceived usefulness, perceived ease of use, and user acceptance of information technology. MIS quarterly, 13(3), 319-340.

Diekmann, A. (2007). Not the first digit! using benford's law to detect fraudulent scientif ic data. Journal of Applied Statistics, 34(3), 321-329.

Field, A.P. (2013). Discovering statistics using IBM SPSS Statistics: and sex and drugs and rock ' $n$ ' roll, $4^{\text {th }}$ ed. London : SAGE Publications,.

Fisher, M. J., \& Marshall, A. P. (2009). Understanding descriptive statistics. Australian Critical Care, 22(2), 93-97.

Fusilier, M., \& Durlabhji, S. (2005). An exploration of student internet use in India. CampusWide Information Systems, 22(4), 233-246.

Gao, L., \& Bai, X. (2014). An empirical study on continuance intention of mobile social networking services. Asia Pacific Journal of Marketing and Logistics, 26(2), 168-189.

Geissbauer, R., Vedso, J., \& Schrauf, S. (2016). Industry 4.0: Building the digital enterprise. Retrieved from PwC Website: https://www. pwc. com/gx/en/industries/industries4.0/landing-page/industry-4.0-building-your-digital-enterprise-april-2016. pdf.

Goethals, G. R., Sorenson, G. J., \& Burns, J. M. (Eds.). (2004). Encyclopedia of leadership. California: Sage Publications.

Gubbi, J., Buyya, R., Marusic, S., \& Palaniswami, M. (2013). Internet of Things (IoT): A vision, architectural elements, and future directions. Future generation computer systems, 29(7), $1645-1660$.

Hair Jr, J. F., Hult, G. T. M., Ringle, C., \& Sarstedt, M. (2014). A Primer on Partial Least Squares Structural Equation Modeling (PLS-SEM), $1^{\text {st }}$ ed. Thousand Oaks: SAGE Publications.

Hair, J. F., Ringle, C. M., \& Sarstedt, M. (2013). Partial least squares structural equation modeling: Rigorous applications, better results and higher acceptance. Long range planning, 46(1-2), 1-12.

Hair, J.F., Sarstedt, M. \& Ringle, C.M. (2017). Partial Least Squares Structural Equation Modeling, Chapter 15: Handbook of Market Research. New York: Springer Publishing. 
Hawk, E.T., Matrisian, L.M., Nelson, W.G., Dorfman, G.S., Stevens, L., Kwok, J., Viner, J., Hautala, J., \& Grad, O. (2008). The Translational Research Working Group Developmental Pathways: Introduction and Overview. Clinical Cancer Research, 14(18), 5664-5671.

Heneman, G.H. \& Patterson, D.G. (1949). Refusal rates and interviewer quality. International Journal of Opinion and Attitude Research, 3(3), 392-398.

Henseler, J., \& Chin, W. W. (2010). A comparison of approaches for the analysis of interaction effects between latent variables using partial least squares path modeling. Structural Equation Modeling, 17(1), 82-109.

Henseler, J., \& Sarstedt, M. (2013). Goodness-of-fit indices for partial least squares path modeling. Computational Statistics, 28(2), 565-580.

Henseler, J., Hubona, G., \& Ray, P. A. (2016). Using PLS path modeling in new technology research: updated guidelines. Industrial management \& data systems.

Henseler, J., Ringle, C. M., \& Sinkovics, R. R. (2009). The use of partial least squares path modeling in international marketing. Advances in International Marketing, 20(1), 277319.

Howard, P.N. (2015). Pax Technica: How the Internet of Things may set us free or lock us up, $1^{\text {st }}$ ed. New Haven: Yale University Press.

Hoy, WK and Curt, A 2016, Quantitative research in education: A primer, $2^{\text {nd }}$ ed. Los Angeles: SAGE Publications.

Hsu, C. L., \& Lin, J. C. C. (2016). An empirical examination of consumer adoption of Internet of Things services: Network externalities and concern for information privacy perspectives. Computers in Human Behavior, 62, 516-527.

Hsu, H. Y., \& Tsou, H. T. (2011). Understanding customer experiences in online blog environments. International Journal of Information Management, 31(6), 510-523.

Hu, L. T., \& Bentler, P. M. (1999). Cutoff criteria for fit indexes in covariance structure analysis: Conventional criteria versus new alternatives. Structural equation modeling: a multidisciplinary journal, 6(1), 1-55.

Hulland, J. (1999). Use of partial least squares (PLS) in strategic management research: A review of four recent studies. Strategic management journal, 20(2), 195-204.

Iacobucci, D., Saldanha, N., \& Deng, X. (2007). A meditation on mediation: Evidence that structural equations models perform better than regressions. Journal of consumer psychology, 17(2), 139-153.

InvestKL 2019, Malaysia gets serious on developing IoT ecosystem, http://www.investkl.gov.my/Relevant_News-@_Malaysia_Gets_Serious_on_Developing_IoT_Ecosystem.aspx

Jahanmir, S. F., \& Cavadas, J. (2018). Factors affecting late adoption of digital innovations. Journal of business research, 88(1), 337-343.

Kaiser, H. F., \& Rice, J. (1974). Little jiffy, mark IV. Educational and psychological measurement, 34(1), 111-117.

Karahoca, A., Karahoca, D., \& Aksöz, M. (2018). Examining intention to adopt to internet of things in healthcare technology products. Kybernetes, 47(4), 742-770.

Khan, R., Khan, S. U., Zaheer, R., \& Khan, S. (2012, December). Future internet: the internet of things architecture, possible applications and key challenges. In 2012 10th international conference on frontiers of information technology (pp. 257-260). IEEE.

Kim, J. B. (2012). An empirical study on consumer first purchase intention in online shopping: integrating initial trust and TAM. Electronic Commerce Research, 12(2), 125-150.

Kline, R. B. (2016). Principles and practice of Structural Equation Modeling, $4^{\text {th }}$ ed. New York: The Guilford Press. 
Lee, W. I., Chiu, Y. T., Liu, C. C., \& Chen, C. Y. (2011). Assessing the effects of consumer involvement and service quality in a self-service setting. Human Factors and Ergonomics in Manufacturing \& Service Industries, 21(5), 504-515.

Likert, R. (1932). A technique for the measurement of attitudes. Archives of psychology, 22(140), 5-55.

Mahbub, M. (2020). A smart farming concept based on smart embedded electronics, internet of things and wireless sensor network. Internet of Things, 9(1), 1-30.

Makkonen, P. (1997, June). Does collaborative hypertext support better engagement in learning of the basics in informatics?. In Proceedings of the 2 nd conference on Integrating technology into computer science education (pp. 130-132).

Marshall, G., \& Jonker, L. (2010). An introduction to descriptive statistics: A review and practical guide. Radiography, 16(4), 1-7.

Miltgen, C. L., Popovič, A., \& Oliveira, T. (2013). Determinants of end-user acceptance of biometrics: Integrating the "Big 3" of technology acceptance with privacy context. Decision Support Systems, 56(1), 103-114.

Newman, D. (2019). Breaking down the six pillars of digital transformation from the CEO's perspective. Retrieved from: https://www.forbes.com/sites/danielnewman/2019/01/02/ breaking-down-the-6-pillars-of-digital-transformation-from-the-ceos-perspective/ \#4998898b6fdc.

O'Brien, H. L., \& Toms, E. G. (2008). What is user engagement? A conceptual framework for defining user engagement with technology. Journal of the American society for Information Science and Technology, 59(6), 938-955.

Ozkan, M., \& Solmaz, B. (2015). The changing face of the employees-generation Z and their perceptions of work (a study applied to university students). Procedia Economics and Finance, 26(1), 476-483.

Park, E., Cho, Y., Han, J., \& Kwon, S. J. (2017). Comprehensive approaches to user acceptance of Internet of Things in a smart home environment. IEEE Internet of Things Journal, 4(6), 2342-2350.

Peppet, S. R. (2014). Regulating the internet of things: first steps toward managing discrimination, privacy, security and consent. Tex. L. Rev., 93(1), 85-178.

Porter, M. E., \& Heppelmann, J. E. (2015). How Smart, Connected Products Are Transforming Companies. Harvard Business Review, 93(10), 96-114.

Preacher, K. J., \& Hayes, A. F. (2004). SPSS and SAS procedures for estimating indirect effects in simple mediation models. Behavior research methods, instruments, \& computers, 36(4), 717-731.

Proctor, R.W. \& Capaldi, E.J. (2008). Why science matters: Understanding the methods of psychological research, $2^{\text {nd }}$ ed. Malden: Blackwell Publishing.

Ramayah, T., Hwa, C.J., Chuah, F., Ting, H. \& Memon, M.A. (2016). Partial Least Squares Structural Equation Modeling (PLS-SEM) using SmartPLS 3.0: An updated and practical

Ridley, M. (2015). The evolution of everything - How new ideas emerge, $1^{\text {st }}$ ed. New York: Harper Perennial.

Ringle, C. M., Sarstedt, M., \& Straub, D. W. (2012). A critical look at the use of PLS-SEM in MIS quarterly. MIS Quarterly, 36(1), 3-14.

Rogers, E.M. (1995). Diffusion of innovations, $4^{\text {th }}$ ed. New York: The Free Press.

Rogers, E.M. (2003). Diffusion of innovations, $5^{\text {th }}$ ed., New York: The Free Press.

Rogers, E. M. (2004). A prospective and retrospective look at the diffusion model. Journal of health communication, 9(S1), 13-19. 
Salvo, M. J. (2002). Critical engagement with technology in the computer classroom. Technical Communication Quarterly, 11(3), 317-337.

Schmidt, E. \& Rosenberg, J. (2014). How Google works, $1^{\text {st }}$ ed. New York: Grand Central Publishing.

Schwab, K. (2016). The Fourth Industrial Revolution. Quality Management Journal, 25(2), $108-109$.

Skelly, T., Fries, K., Linnett, B., Nass, C., \& Reeves, B. (1994, April). Seductive interfaces: Satisfying a mass audience. In Proceedings of the ACM CHI 94 Human Factors in Computing Systems Conference, 24-28 April 1994, Boston (pp. 359-360).

Sosik, J. J., Kahai, S. S., \& Piovoso, M. J. (2009). Silver bullet or voodoo statistics? A primer for using the partial least squares data analytic technique in group and organization research. Group \& Organization Management, 34(1), 5-36.

Stamm, B.V. (2008). Managing innovation, design and creativity, $2^{\text {nd }}$ ed. New Jersey: Wiley.

Sundmaeker, H., Guillemin, P., Friess, P., \& Woelfflé, S. (2010). Vision and challenges for realising the Internet of Things. Cluster of European Research Projects on the Internet of Things, European Commision, 3(3), 34-36.

Tianbo, Z. (2012, November). The internet of things promoting higher education revolution. In Proceedings of the 2012 Fourth International Conference on Multimedia Information Networking and Security (pp. 790-793). IEEE.

Heinis, T. B., Hilario, J., \& Meboldt, M. (2018). Empirical study on innovation motivators and inhibitors of Internet of Things applications for industrial manufacturing enterprises. Journal of Innovation and Entrepreneurship, 7(1), 10.

Trott, P. (2017). Innovation management and new product development, $6^{\text {th }}$ ed. London: Pearson.

Uckelmann, D., Harrison, M., \& Michahelles, F. (2011). An architectural approach towards the future Internet of Thing, $1^{\text {st }}$ ed. New York: Springer.

Uzelac, A. (2010). Digital culture as a converging paradigm for technology and culture: Challenges for the culture sector. Digithum, 12, 28-35.

Vaidya, S., Ambad, P., \& Bhosle, S. (2018). Industry 4.0-a glimpse. Procedia Manufacturing, 20, 233-238.

Veryzer, R. W. (2003). Marketing and the development of innovative new products. In The International Handbook on Innovation (pp. 845-855). Amsterdam: Elsevier Science Ltd.

Wang, X., Li, J., Yang, M., Chen, Y., \& Xu, X. (2018). An empirical study on the factors influencing mobile library usage in IoT era. Library Hi Tech, 36(4), 605-621.

Wu, J. H., \& Wang, S. C. (2005). What drives mobile commerce?: An empirical evaluation of the revised technology acceptance model. Information \& management, 42(5), 719-729.

Mun, Y. Y., Jackson, J. D., Park, J. S., \& Probst, J. C. (2006). Understanding information technology acceptance by individual professionals: Toward an integrative view. Information \& Management, 43(3), 350-363.

Yoon, J. S. (2002). Teacher characteristics as predictors of teacher-student relationships: Stress, negative affect, and self-efficacy. Social Behavior and Personality: an international journal, 30(5), 485-493.

Zikmund, W.G., Babin, B.J., Carr, J.C. \& Griffin, M. (2010). Business Research Methods, $8^{\text {th }}$ ed., Boston: Cengage Learning. 
